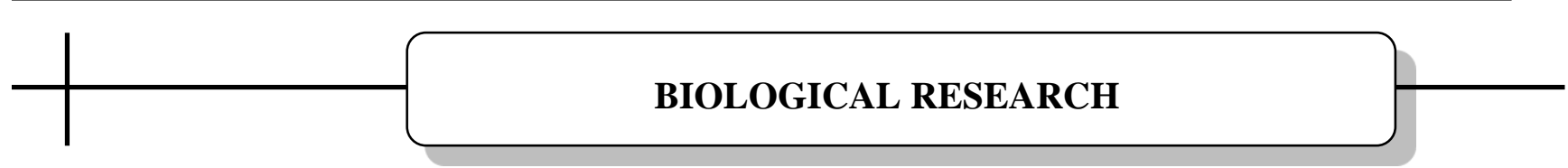

UDC 547.99.4722-4725:615.246.9

DOI: 10.15587/2519-8025.2021.235095

\title{
THE STUDY OF THE ANTI-INFLAMMATORY PROPERTIES OF CAROTENOID LIQUID EXTRACTS ON THE MODEL OF ADJUVANT-INDUCED INFLAMMATION
}

\author{
Yurii Boiko, Mohammed Ayat, Irina Boiko, Alexey Shandra
}

The search for new anti-inflammatory substances is an important area of pharmacology. Plant carotenoids have many positive biological effects and are of interest as potential anti-inflammatory agents.

The aim. To study the anti-inflammatory properties of extractive carotenoids from fruits of Capsicum annuum L. on the model of adjuvant-induced inflammation.

Materials and methods. The fruits of Capsicum annum L. were used as the plant raw material. Carotenoids were obtained by the extractive method. The model of adjuvant-induced inflammation was reproduced in young female rats. The dynamics of changes in the volume of the inflammatory edema and the total number of blood leukocytes were studied.

Results and discussion. A decrease in edema in nonspecific inflammation was observed on day 15 during the therapy with carotenoid extracts ( $\Delta 1.01 \pm 0.08$ in treatment group; $\Delta 1.28 \pm 0.08$ in control group). For specific inflammation, edema reduction when using carotenoids occurred on day $30(\Delta 0.047 \pm 0.015$ in treatment group; $40.073 \pm 0.012$ in control group). A decrease in leukocytosis occurred on days 20 and 30 of the treatment for non-specific and specific inflammation, respectively. The mechanisms of the anti-inflammatory action of carotenoids are presumably associated with the antioxidant effect and the ability to affect the production of pro-inflammatory cytokines.

Conclusions. Extractive carotenoids from the fruits of Capsicum annuum L. have the anti-inflammatory activity in the case of adjuvant-induced inflammation. Treatment with Capsicum annuum L. extract reduced inflammatory edema and total leukocyte count

Keywords: carotenoids; Capsicum annuum L.; adjuvant-induced inflammation

\section{How to cite:}

Boiko, Y., Ayat, M., Boiko, I., Shandra, A. (2021). The study of the anti-inflammatory properties of carotenoid liquid extracts on the model of adjuvant-induced inflammation. ScienceRise: Biological Science, 2 (27), 04-09. doi: http://doi.org/10.15587/2519-8025.2021.235095

\section{Introduction}

Pharmacology and pharmaceutical chemistry uses four priority areas for the development of medicinal substances:

1) search for new targets and mechanisms of action for already known drugs;

2) directed chemical design for the synthesis of substances with predetermined pharmacological properties;

3) screening among a large number of natural compounds, banks of chemicals or peptide, nucleotide and other libraries; cules [1].

4) modification of already known active mole-

It should be noted that the new pharmacological compounds allow obtaining only the second or third route. From the above, it becomes clear that researchers pay close attention to substances of natural, in particular plant, origin [2]. Studies of the anti-inflammatory proper- ties of plant compounds have become especially widespread $[3,4]$.

Carotenoids are a numerous class of polyunsaturated derivatives of tetraterpenes of plant origin, which have distinct antioxidant properties [5, 6]. Reduction of oxidative stress allows the use of carotenoids as substances that reduce alternative phenomena in the area of inflammation, namely: carotenoids are a free radical trap, neutralize reactive oxygen species, and reduce lipid peroxidation [6]. A significant amount of carotenoids is contained in the fruits of Capsicum annuum $L$. and depends on growing conditions and degree of ripeness $[7,8]$. Studies of carotenoid extracts from the fruits of different species of Capsicum have shown their ability to reduce the total number of reactive oxygen species and free radicals [9]. It should be noted that the fruits of pepper contain a large number of other substances with antioxidant activity - chlorophyll 
[7], phenols [10], capsaicinoids [10], vitamins [11]. The effect of carotenoids on inflammatory processes is not limited to antioxidant action: carotenoids are able to trap harmful radiation [12], have membraneprotective properties [13], inhibit the cascade of proinflammatory cytokines [14].

The aim of this study was to investigate the antiinflammatory effect of liquid carotenoid extract from the fruits of Capsicum annuum $L$. in a model of adjuvantinduced inflammation.

\section{Materials and methods} 2019-2020.

The study was conducted in the period

Animals. The study was conducted on female rats weighing 200-240 g from the experimental biological clinic of Odessa National Medical University, which were kept at a temperature of $20-22{ }^{\circ} \mathrm{C}$, relative humidity of 40-50\% and 12-hour world day, with free access to food and water. The study was performed in accordance with the recommendations of the European Convention on Experiments on Animals and approved by the Commission on Bioethics of the Odessa National Medical University (Minutes of October 10, 2008, No. 84). In experiments with laboratory animals also followed the "Rules of performance of works using experimental animals", approved by the order of the Ministry of Health of Ukraine No. 249 from 01.03.2012 and the law of Ukraine No. 3477-IV "On protection of animals from cruel treatment" (as amended from 15.12.2009 and from 16.10.2012).

Obtaining liquid extracts of carotenoids. As a source of carotenoids used ripe fruits of Capsicum annuиm L. variety "Ukrainian Bitter". The fruits were air-dried to constant weight, after which the stones and the green part were removed. The remaining fruit mass was crushed and filled with acetone $\left(5^{\circ} \mathrm{C}\right)$ in a ratio of 1:20. The obtained extract was filtered through a filter № 4 under a vacuum pump. The filtrate was transferred to a separatory funnel containing a mixture of petroleum ether and water. Mixed without shaking, after which the hydrogen part was removed. The remaining mixture was washed several times with water. Subsequently, the solution was stored in the dark at a temperature not exceeding $5{ }^{\circ} \mathrm{C}$. Determination of carotenoid concentration was performed by spectrophotometric method. Before further therapeutic use, the extract was concentrated at low temperatures $\left(<40{ }^{\circ} \mathrm{C}\right)$, the resulting concentrate was dissolved in $96^{\circ}$ ethyl alcohol. The final concentration of carotenoids in the alcohol solution was $10 \mathrm{mg} / \mathrm{ml}$.

Experimental model of rheumatoid inflammation. To induce inflammatory arthritis, all animals under plantar aponeurosis were administered $0.1 \mathrm{ml}$ of complete Freund's adjuvant under light ether anesthesia. The animals were then grouped into three groups, 10 animals each. The first group was experimental and treated with liquid carotenoid extract. The second group was positively controlled and treated with a reference drug. The third group was negatively controlled and did not receive treatment.

To assess the therapeutic effect, morphological changes in the area of inflammation were investigated.
The volume of edema was measured with a digital plethysmometer (37140, Ugo Basile, Italy). The antiedematous effect was calculated by the formula: $\operatorname{AE}(\%)=100 \%-\left(\mathrm{V}_{\mathrm{o}} / \mathrm{V}_{\mathrm{c}} * 100 \%\right)$,

where $\mathrm{AE}$ - anti-edema effect in $\% ; \mathrm{V}_{\mathrm{o}}$ - the average difference between the volumes of the inflamed and intact limb in the animals of the experimental group, $\mathrm{ml} ; \mathrm{V}_{\mathrm{c}}-$ the average difference between the volumes of the inflamed and intact limb in animals of the control group, ml.

Leukocytes were counted in Goryaev's chamber.

The relative change in the number of leukocytes in peripheral blood against the control group was calculated by the formula:

$$
\operatorname{IL}(\%)=100 \%-\left(\mathrm{L}_{\mathrm{o}} / \mathrm{L}_{\mathrm{c}} * 100 \%\right) \text {, }
$$

where IL - relative change in the number of peripheral blood leukocytes against the indicators of animals in the control group in $\% ; \mathrm{L}_{\mathrm{o}}$ - the average value of the difference between leukocytes for inflammation and intact in animals of the experimental group, $\mathrm{G} / \mathrm{l} ; \mathrm{L}_{\mathrm{c}}-$ the average value of the difference between leukocytes in inflammation and intact in animals of the control group, G/l.

Treatment and dosage regimen. The experimental group and the positive control group were divided into two levels of subgroups. The first subgroups of both groups received treatment one day after the induction of the inflammatory process. The second subgroup received treatment after 10 days from the introduction of the adjuvant, treated both the limb with the inflammatory process and the contralateral limb, which developed a specific immune inflammation. During the treatment of animals of the experimental group, the limb to the site of inflammation was immersed in an alcoholic solution of carotenoids. Immersion was performed for 10 minutes, once a day, daily. "Diclofenac-viola" gel was used as a reference drug, a registered drug in a mild form containing $1 \%$ diclofenac sodium, which was rubbed into the sites of inflammation. Mode and dosage $-5 \mathrm{mg} / \mathrm{kg}$, once a day.

Statistical analysis. The distribution of animals in the experimental groups was random. The normality of the distribution was confirmed by the KolmogorovSmirnov test. Because all groups had a normal distribution, analysis of variance was performed using Student's t-test with Bonferoni correction. The calculations were performed in the Free Office software package.

\section{Research results}

After the introduction of phlogogen we observed a pronounced inflammatory reaction. In addition to edema, redness at the injection site, there was a partial loss of functional activity of the affected joints. The animals moved less around the cage, the movements were slower, and the animals tried not to load the limb into which the adjuvant was administered. These phenomena were fully or partially observed by the end of the experiment in all groups of animals.

Data on the dynamics of morphological changes (volume of edema) of non-specific inflammatory process caused by the introduction of complete Freund's adjuvant in the conditions of experimental treatment with liquid carotenoid extract are given in Table 1. 
Table 1

Indicators of changes in the volume of the contralateral limb in the area of inflammation (metatarsal joint) and antiedema efficacy of drugs used for non-specific inflammation $(M \pm m, n=5)$

\begin{tabular}{|c|c|c|c|c|c|}
\hline \multirow{2}{*}{$\begin{array}{c}\text { Time after phlogo- } \\
\text { gen injection (days) }\end{array}$} & \multicolumn{2}{|c|}{$\begin{array}{c}\text { The difference }(\Delta) \text { between the volume of the inflamed and } \\
\text { intact limb (before inflammation), ml }\end{array}$} & \multicolumn{2}{c|}{ Anti-edematous effect, \% } \\
\cline { 2 - 6 } & $\begin{array}{c}\text { Control } \\
\text { group }\end{array}$ & $\begin{array}{c}\text { Treatment group with liq- } \\
\text { uid carotenoid extract }\end{array}$ & $\begin{array}{c}\text { Diclofenac treat- } \\
\text { ment group }\end{array}$ & $\begin{array}{c}\text { Liquid carote- } \\
\text { noid extract }\end{array}$ & Diclofenac \\
\hline 1 & $0.79 \pm 0.09$ & $0.82 \pm 0.11$ & $0.81 \pm 0.08$ & -3.80 & -2.53 \\
\hline 2 & $0.94 \pm 0.10$ & $0.9 \pm 0.13$ & $0.89 \pm 0.11$ & 4.26 & 5.32 \\
\hline 3 & $1.22 \pm 0.05$ & $1.21 \pm 0.09$ & $1.15 \pm 0.18$ & 0.82 & 5.74 \\
\hline 5 & $1.38 \pm 0.11$ & $1.34 \pm 0.1$ & $1.24 \pm 0.07$ & 2.90 & 10.14 \\
\hline 7 & $1.39 \pm 0.1$ & $1.32 \pm 0.12$ & $1.34 \pm 0.01$ & 5.04 & 3.60 \\
\hline 10 & $0.99 \pm 0.12$ & $0.95 \pm 0.15$ & $1.06 \pm 0.16$ & 4.04 & -7.07 \\
\hline 12 & $1.3 \pm 0.13$ & $1.1 \pm 0.14$ & $0.92 \pm 0.14^{*}$ & 15.38 & 29.23 \\
\hline 15 & $1.28 \pm 0.08$ & $1.01 \pm 0.08^{*}$ & $0.94 \pm 0.11^{*}$ & 21.09 & 26.56 \\
\hline 20 & $1.40 \pm 0.12$ & $0.95 \pm 0.06^{*}$ & $0.85 \pm 0.12^{*}$ & 32.14 & 39.29 \\
\hline 25 & $1.42 \pm 0.07$ & $0.9 \pm 0.09^{*}$ & $0.77 \pm 0.03^{* \#}$ & 36.62 & 45.77 \\
\hline 30 & $1.35 \pm 0.12$ & $0.85 \pm 0.06^{*}$ & $0.74 \pm 0.07^{* \#}$ & 37.04 & 45.19 \\
\hline
\end{tabular}

Note: * - significance of differences between experimental and control group $p \leq 0.05$; \# - significance of differences between the group treated with liquid extract and the group treated with diclofenac $p \leq 0.05$

The development of non-specific inflammatory process was observed from the first day after the introduction of adjuvant, the volume of the paw increased by $0.79-0.82 \mathrm{ml}$ in animals of the experimental groups. Subsequently, two peaks of edema were observed: at the end of the first week - an increase in volume by 1.34 $1.39 \mathrm{ml}$ against intact values, after 25 days of inflammation - an increase in volume by 0.74-1.42 ml. Comparing the used drugs, we can conclude about the more pronounced therapeutic efficacy of diclofenac against liquid carotenoid extract. The use of diclofenac after 12 days of treatment caused a statistically significant reduction in edema $(29 \%, t=4.4)$ against the control group. For the group of animals treated with liquid carotenoid extract, statistically significant changes against the control group of animals were observed on day 15 of treatment $(21.09 \%$, $\mathrm{t}=5.33$ ). At the end of treatment (30 days), a greater therapeutic effect of diclofenac against liquid carotenoid extract was observed in the treatment of adjuvant-induced inflammation.

Of no less interest is the anti-inflammatory effect of the liquid extract of carotenoids in the case of specific autoimmune inflammation affecting the joints of the contralateral limb. Relevant data on the anti-edematous effect of anti-inflammatory drugs for specific inflammation are given in Table 2 .

Table 2

Indicators of changes in the volume of the contralateral limb in the area of inflammation (metatarsal joint) and antiedema efficacy of drugs used for specific inflammation $(M \pm m, n=5)$

\begin{tabular}{|c|c|c|c|c|c|}
\hline \multirow{2}{*}{$\begin{array}{c}\text { Time after phlogo- } \\
\text { gen injection (days) }\end{array}$} & \multicolumn{2}{|c|}{$\begin{array}{c}\text { The difference }(\Delta) \text { between the volume of the inflamed and in- } \\
\text { tact limb (before inflammation), ml }\end{array}$} & \multicolumn{2}{c|}{ Anti-edematous effect, \% } \\
\cline { 2 - 6 } & $\begin{array}{c}\text { Control } \\
\text { group }\end{array}$ & $\begin{array}{c}\text { Treatment group with } \\
\text { liquid carotenoid extract }\end{array}$ & $\begin{array}{c}\text { Diclofenac treat- } \\
\text { ment group }\end{array}$ & $\begin{array}{c}\text { Liquid carote- } \\
\text { noid extract }\end{array}$ & Diclofenac \\
\hline 10 & $0.011 \pm 0.005$ & $0.014 \pm 0.008$ & $0.014 \pm 0.007$ & -27.27 & -27.27 \\
\hline 12 & $0.014 \pm 0.017$ & $0.029 \pm 0.01$ & $0.016 \pm 0.007$ & -107.14 & -14.29 \\
\hline 15 & $0.03 \pm 0.011$ & $0.052 \pm 0.015$ & $0.03 \pm 0.01$ & -73.33 & 0.00 \\
\hline 20 & $0.095 \pm 0.02$ & $0.056 \pm 0.09$ & $0.028 \pm 0.022^{*}$ & 41.05 & 70.53 \\
\hline 25 & $0.074 \pm 0.023$ & $0.046 \pm 0.08$ & $0.035 \pm 0.021 *$ & 37.84 & 52.70 \\
\hline 30 & $0.073 \pm 0.012$ & $0.047 \pm 0.015^{*}$ & $0.055 \pm 0.016$ & 35.62 & 24.66 \\
\hline
\end{tabular}

Note: * significance of differences between experimental and control group $p \leq 0.05$

The first signs of specific inflammation (edema, soreness) in the control group of animals appeared on day 10 , but were clearly manifested on day 20 (increase in the volume of the metatarsal joint (art. tarsi) by $0.095 \mathrm{ml}$ ) after the introduction of phlogogen. The antiedematous effect with the use of diclofenac was observed from 20 days, and for carotenoid extract - from 30 days after induction of inflammation.

The intensity of anti-edematous effect decreased from 20 to 30 days of treatment for diclofenac from
$70.53 \%$ to $24.66 \%$, and for carotenoid extract from 41.05 to $35.62 \%$.

The obligatory component of the inflammatory reaction is leukocyte. The change in the total number of blood leukocytes allows characterizing the inflammatory process and the effectiveness of the selected treatment. In the Table 3 and 4 the dynamics of changes in the number of blood leukocytes in non-specific and specific inflammation under conditions of treatment with diclofenac and carotenoid extract are shown. 
Dynamics of changes in the total number of peripheral blood leukocytes in non-specific inflammation $(M \pm m, n=5)$

\begin{tabular}{l|l} 
Time after & The difference $(\Delta)$ between the total number of leukocytes in
\end{tabular} phlogogen injec- the blood during inflammation and before the induction of inReduction of the number of leution (days) flammation

\begin{tabular}{|c|c|c|c|c|c|}
\cline { 2 - 5 } & $\begin{array}{c}\text { Control } \\
\text { group }\end{array}$ & $\begin{array}{c}\text { Treatment group with } \\
\text { liquid carotenoid extract }\end{array}$ & $\begin{array}{c}\text { Diclofenac treat- } \\
\text { ment group }\end{array}$ & $\begin{array}{c}\text { Liquid carotenoid } \\
\text { extract }\end{array}$ & Diclofenac \\
\hline 1 & $11.5 \pm 1.8$ & $10.9 \pm 4.1$ & $10.2 \pm 1.5$ & 5.22 & 11.30 \\
\hline 2 & $12.3 \pm 4.7$ & $11.4 \pm 1.8$ & $12.8 \pm 3.4$ & 7.32 & -4.07 \\
\hline 3 & $13.7 \pm 1.3$ & $14.6 \pm 4.5$ & $14.5 \pm 4.3$ & -6.57 & -5.84 \\
\hline 5 & $13.9 \pm 3.6$ & $15.2 \pm 4.8$ & $15.7 \pm 4.2$ & -9.35 & -12.95 \\
\hline 7 & $18.3 \pm 1.8$ & $17.3 \pm 2.7$ & $16.9 \pm 3.5$ & 5.46 & 7.65 \\
\hline 10 & $26.8 \pm 1.3$ & $22.3 \pm 3.6^{*}$ & $20.7 \pm 4.7^{*}$ & 16.79 & 22.76 \\
\hline 12 & $31.5 \pm 1.1$ & $25.5 \pm 3.9^{*}$ & $23.4 \pm 2.2^{*}$ & 19.05 & 25.71 \\
\hline 15 & $34.3 \pm 2.2$ & $27.9 \pm 4.5$ & $25.7 \pm 2.0$ & 18.66 & 25.07 \\
\hline 20 & $30.7 \pm 1.6$ & $29.3 \pm 1.9$ & $26.3 \pm 4.7$ & 4.56 & 14.33 \\
\hline 25 & $24.9 \pm 1.1$ & $26.4 \pm 3.7$ & $22.2 \pm 3.6$ & -6.02 & 10.84 \\
\hline 30 & $27.3 \pm 1.7$ & $23.6 \pm 4.0$ & $21.7 \pm 2.2^{*}$ & 13.55 & 20.51 \\
\hline
\end{tabular}

Note: $*$ - significance of differences between experimental and control group $p \leq 0.05$

Table 4

Dynamics of changes in the total number of peripheral blood leukocytes with specific inflammation $(M \pm m, n=5)$

\begin{tabular}{|c|c|c|c|c|c|}
\hline \multirow{2}{*}{$\begin{array}{c}\text { Time after } \\
\text { phlogogen injec- } \\
\text { tion (days) }\end{array}$} & \multicolumn{2}{|c|}{$\begin{array}{c}\text { The difference }(\Delta) \text { between the total number of leukocytes in } \\
\text { the blood during inflammation and before the induction of in- } \\
\text { flammation }\end{array}$} & \multicolumn{2}{|c|}{$\begin{array}{c}\text { Reduction of the number of leu- } \\
\text { kocytes relative to control, } \%\end{array}$} \\
\cline { 2 - 6 } & $\begin{array}{c}\text { Control } \\
\text { group }\end{array}$ & $\begin{array}{c}\text { Treatment group with } \\
\text { liquid carotenoid extract }\end{array}$ & $\begin{array}{c}\text { Diclofenac treat- } \\
\text { ment group }\end{array}$ & $\begin{array}{c}\text { Liquid carotenoid } \\
\text { extract }\end{array}$ & Diclofenac \\
\hline 10 & $22.3 \pm 3.2$ & $20.6 \pm 1.6$ & $24.7 \pm 3.6$ & 7.62 & -10.76 \\
\hline 12 & $26.7 \pm 2.6$ & $24.8 \pm 2.7$ & $25.9 \pm 2.7$ & 7.12 & 3.00 \\
\hline 15 & $30.5 \pm 4.8$ & $27.3 \pm 3.4$ & $23.2 \pm 2.2^{*}$ & 10.49 & 23.93 \\
\hline 20 & $32.8 \pm 2.9$ & $26.4 \pm 2.7^{*}$ & $24.6 \pm 2.9^{*}$ & 19.51 & 25.00 \\
\hline 25 & $30.7 \pm 3.7$ & $23.1 \pm 1.9^{*}$ & $20.6 \pm 3.1^{*}$ & 24.76 & 32.90 \\
\hline 30 & $28.5 \pm 3.7$ & $21.6 \pm 3.6^{*}$ & $23.3 \pm 1.7^{*}$ & 24.21 & 18.25 \\
\hline
\end{tabular}

Note: *- significance of differences between experimental and control group $p \leq 0.05$

\section{Discussion of research results}

Non-specific and specific adjuvant-induced inflammation caused severe leukocytosis, the number of leukocytes increased 2-3 times in the studied groups of animals. The use of diclofenac and carotenoid extract in the case of non-specific inflammation caused a decrease in the number of leukocytes, which was not statistically significant. In contrast, treatment with diclofenac and extractive carotenoids resulted in a statistically significant reduction in white blood cells from day 20 of treatment. With the use of diclofenac, the number of leukocytes in the blood of experimental animals decreased by 18.25$32.9 \%$ against the control group, for carotenoid extract by $19.51-24.76 \%$, respectively.

Adjuvant inflammation consists of non-specific and specific stages [15]. The non-specific stage of the inflammatory process begins immediately after the introduction of adjuvant and is caused by innate immune reactions. The reduction of edema-exudative phenomena observed due to the action of carotenoids after 15 days of treatment may be due to the stabilization of membranes (cellular, mitochondrial, lysosomal). Direct antioxidant action reduces the intensity of leukocyte-induced oxidative stress and the resulting cellular and subcellular lesions, and carotenoids inhibit macrophage NO synthase [16]. Carotenoids inhibit the activation of macrophages and reduce the production of macrophage cytokines (IL-
$1 \beta$, IL-6, TNF- $\alpha$ ) [16]. The decrease in the total number of leukocytes observed from 10 days of treatment (22.3 $\pm 3.6 \mathrm{G} / 1$ experimental group; $26.8 \pm 1.3 \mathrm{G} / 1$, control group) can be explained both by inhibition of IL-1 and TNF- $\alpha$ production, and by some normalization of metabolic processes in the area of inflammation.

At 8-10 days after administration of complete Freund's adjuvant, a specific autoimmune process develops, which involves macrophages, CD4+Th1, CD4+Th2, plasma cells and synoviocytes. Central cytokines that regulate the processes of differentiation, proliferation and activation for the above cells are IL-1 and TNF- $\alpha$ [17]. Carotenoids are known to reduce IL-1-induced $\mathrm{PGE}_{2}$ and MMP-1 production, which are important factors in joint damage [18]. The activity of MMP-1 is also influenced by bacterial liposaccharides and factors that alter the stability of membranes [19]. In addition to inhibiting the IL-1-dependent mechanism of MMP-1 activation, carotenoids have a membranestabilizing effect, which can further reduce the activity of this enzyme [13]. MMP-1 is involved in the destruction of the intercellular matrix in the case of arthritis, breaks down collagen (type-1, -2 and -3), fibronectin, vitronectin, proteoglycans [20]. Decreased MMP-1 activity may be a significant part of the therapeutic effect of carotenoids in the case of adjuvant-induced joint damage. $\mathrm{PGE}_{2}$ is ambiguously involved in the pathogenesis of rheumatoid arthritis, because it has pro-inflammatory (stimulation of vascular endothelial 
growth factor production, sensitization to histamine and kinins) and anti-inflammatory properties (reduces the production of TNF- $\alpha$, IL-6, IL-8, IL-12) [21]. However, in experiments on a collagen model of arthritis in mice, the main proinflammatory effect of $\mathrm{PGE}_{2}$ was demonstrated [22]. The study draws attention to the fact that local signs of specific inflammation began to decrease probably only on the 30th day of treatment, while the decrease in the intensity of the increase in the number of leukocytes occurred on the 20th day. Probably, carotenoids had a more pronounced systemic anti-inflammatory effect than local.

Study limitations are a consequence of the used inflammatory model, which allows assessing the effect of carotenoids on autoimmune inflammation, but ignores the possible effects on other components of the inflammatory process.

Prospects for further research. Further studies of the action of carotenoids on potential targets in the inflammatory focus, as well as the influence of carotenoids on inflammatory processes with other types of pathogenesis look promising.

\section{Conclusions}

1. A study showed that extractive carotenoids from the fruits of Capsicum annuum $L$. have antiinflammatory effects in the case of adjuvant-induced inflammation. The anti-edematous effect was observed from 15 days after the start of treatment in the case of nonspecific inflammation and was $21-37 \%$.

2. Local anti-inflammatory effect of carotenoids in the case of specific inflammation was manifested on the 30th day of treatment. The anti-edematous effect was $35.6 \%$.

3 . The systemic effect of carotenoids on the leukocyte fraction of blood was not recorded in the case of non-specific inflammation, but in the treatment of specific inflammation, there was a decrease in blood leukocytes by $19.5-24.2 \%$ compared with animals in the control group.

4. The mechanisms of anti-inflammatory action of carotenoids may be associated with antioxidant and membrane-stabilizing effects, the ability to affect macrophage activity and the production of pro-inflammatory cytokines.

\section{Conflict of interests}

The authors declare that they have no conflicts of interest.

\section{Financing}

The experimental work was carried out in the framework of the planned unfunded scientific topic of the Department of Physiology of Odessa National Medical University.

\section{References}

1. Katzung, B. G., Trevor, A. J. (Eds.) (2015). Basic \& clinical pharmacology, New York: McGraw-Hill, 753-756.

2. Agrawal, D. C., Tsay, H. S., Shyur, L. F., Wu, Y. C., Wang, S. Y. (Eds.) (2017). Medicinal Plants and Fungi: Recent Advances in Research and Development. Vol. 4. Springer, 557. doi: http://doi.org/10.1007/978-981-10-5978-0

3. Jain, P., Pandey, R., Shukla, S. S. (2015). Inflammation: Natural resources and its applications. Springer, 175. doi: http://doi.org/10.1007/978-81-322-2163-0

4. Alamgir, A. N. M. (2018). Therapeutic Use of Medicinal Plants and their Extracts: Volume 2: Phytochemistry and Bioactive Compounds. Vol. 74. Springer, 849. doi: http://doi.org/10.1007/978-3-319-92387-1

5. Chandrasekara, A., Shahidi, F. (2018). Herbal beverages: Bioactive compounds and their role in disease risk reduction- A review. Journal of Traditional and Complementary Medicine, 8 (4), 451-458. doi: http://doi.org/10.1016/j.jtcme.2017.08.006

6. Kiokias, S., Proestos, C., Oreopoulou, V. (2018). Effect of Natural Food Antioxidants against LDL and DNA Oxidative Changes. Antioxidants, 7 (10), 133. doi: http://doi.org/10.3390/antiox7100133

7. Cervantes-Paz, B., Yahia, E. M., de Jesús Ornelas-Paz, J., Victoria-Campos, C. I., Ibarra-Junquera, V., Pérez-Martínez, J. D., Escalante-Minakata, P. (2014). Antioxidant activity and content of chlorophylls and carotenoids in raw and heat-processed Jalapeño peppers at intermediate stages of ripening. Food Chemistry, 146, 188-196. doi: http://doi.org/10.1016/j.foodchem.2013.09.060

8. Cervantes-Paz, B., Yahia, E. M., Ornelas-Paz, J. de J., Gardea-Béjar, A. A., Ibarra-Junquera, V., Pérez-Martínez, J. D. (2012). Effect of Heat Processing on the Profile of Pigments and Antioxidant Capacity of Green and Red Jalapeño Peppers. Journal of Agricultural and Food Chemistry, 60 (43), 10822-10833. doi: http://doi.org/10.1021/jf303091u

9. Alvarez-Parrilla, E., de la Rosa, L. A., Amarowicz, R., Shahidi, F. (2011). Antioxidant Activity of Fresh and Processed Jalapeño and Serrano Peppers. Journal of Agricultural and Food Chemistry, 59 (1), 163-173. doi: http://doi.org/10.1021/jf103434u

10. Ornelas-Paz, J. de J., Martínez-Burrola, J. M., Ruiz-Cruz, S., Santana-Rodríguez, V., Ibarra-Junquera, V., Olivas, G. I., Pérez-Martínez, J. D. (2010). Effect of cooking on the capsaicinoids and phenolics contents of Mexican peppers. Food Chemistry, 119 (4), 1619-1625. doi: http://doi.org/10.1016/j.foodchem.2009.09.054

11. Howard, L. R., Smith, R. T., Wagner, A. B., Villalon, B., Burns, E. E. (1994). Provitamin A and Ascorbic Acid Content of Fresh Pepper Cultivars (Capsicum annuum) and Processed Jalapeños. Journal of Food Science, 59 (2), 362-365. doi: http://doi.org/10.1111/j.13652621.1994.tb06967.x

12. Junghans, A., Sies, H., Stahl, W. (2001). Macular Pigments Lutein and Zeaxanthin as Blue Light Filters Studied in Liposomes. Archives of Biochemistry and Biophysics, 391 (2), 160-164. doi: http://doi.org/10.1006/abbi.2001.2411

13. Subczynski, W. K., Wisniewska, A., Widomska, J. (2010). Location of macular xanthophylls in the most vulnerable regions of photoreceptor outer-segment membranes. Archives of Biochemistry and Biophysics, 504 (1), 61-66. doi: http://doi.org/10.1016/ j.abb.2010.05.015

14. Chung, R. W. S., Leanderson, P., Lundberg, A. K., Jonasson, L. (2017). Lutein exerts anti-inflammatory effects in patients with coronary artery disease. Atherosclerosis, 262, 87-93. doi: http://doi.org/10.1016/j.atherosclerosis.2017.05.008

15. Henderson, B., Edwards, J. G., Pettipher, E. R. (Eds.) (1995). Mechanisms and models in rheumatoid arthritis. Academic Press, 563. doi: http://doi.org/10.1016/b978-0-12-340440-4.x5031-4

16. Firdous, A. P., Kuttan, G., Kuttan, R. (2015). Anti-inflammatory potential of carotenoidmeso-zeaxanthin and its mode of action. Pharmaceutical Biology, 53 (7), 961-967. doi: http://doi.org/10.3109/13880209.2014.950673

17. Klippel, D. Kh., Stoun, D. Kh., Krofford, L. D. (Eds.) (2014). Revmaticheskie zabolevaniya. Vol. 2. Zabolevanie kostey i sustavov. Moscow: GEOTAR-Media, 520. 
18. Fuller, B., Smith, D., Howerton, A., Kern, D. (2006). Anti-inflammatory effects of CoQ10 and colorless carotenoids. Journal of Cosmetic Dermatology, 5 (1), 30-38. doi: http://doi.org/10.1111/j.1473-2165.2006.00220.x

19. Demkin, S. A., Malanin, D. A., Rogova, L. N., Snigur, G. L., Grigorieva, N. V. Baydova, K. V. (2017). Metalloproteinases 1 and 13 as markers of destructive and proliferative processes in the articular cartilage in experimental osteoarthritis. Journal of Volgograd State Medical University, 61 (1), 69-73. doi: http://doi.org/10.19163/1994-9480-2017-1(61)-69-73

20. Arakaki, P. A., Marques, M. R., Santos, M. C. L. G. (2009). MMP-1 polymorphism and its relationship to pathological processes. Journal of Biosciences, 34 (2), 313-320. doi: http://doi.org/10.1007/s12038-009-0035-1

21. Akaogi, J., Nozaki, T., Satoh, M., Yamada, H. (2006). Role of PGE2 and EP Receptors in the Pathogenesis of Rheumatoid Arthritis and as a Novel Therapeutic Strategy. Endocrine, Metabolic \& Immune Disorders - Drug Targets, 6 (4), 383-394. doi: http://doi.org/10.2174/187153006779025711

22. Myers, L. K., Kang, A. H., Postlethwaite, A. E., Rosloniec, E. F., Morham, S. G., Shlopov, B. V. (2000). The genetic ablation of cyclooxygenase 2 prevents the development of autoimmune arthritis. Arthritis \& Rheumatism, 43 (12), 2687-2693. doi: http://doi.org/10.1002/1529-0131(200012)43:12<2687::aid-anr8>3.0.co;2-9

Received date 27.04.2021

Accepted date 03.06.2021

Published date 30.06.2021

Yurii Boiko*, PhD, Associate Professor, Department of Physiology, Pathological Physiology and Biochemistry, Odessa State Agrarian University, Kanatna str., 99, Odessa, Ukraine, 65039

Mohammed Ayat, Postgraduate Student, Department of Organic and Pharmaceutical Chemistry, Odessa Polytechnic State University, Shevchenko ave., 1, Odessa, Ukraine, 65044

Irina Boiko, PhD, Associate Professor, Department of Pharmacology and Pharmacognosy, Odessa National Medical University, Valihovsky lane, 2, Odessa, Ukraine, 65082

Alexey Shandra, Doctor of Medical Sciences, Professor, Head of Department, Department of Physiology, Odessa National Medical University, Valihovsky lane, 2, Odessa, Ukraine, 65082

*Corresponding author: Yurii Boiko, e-mail: yuriyalexb@gmail.com 